\title{
IMPACT OF SIMPLE VIRTUAL TECHNOLOGY APPLICATION IN ARCHITECTURAL EDUCATION
}

\author{
Bramasta Putra Redyantanu ${ }^{1 *}$, Altrerosje Asri ${ }^{1}$ \\ ${ }^{1}$ Department of Architecture, Petra Christian University, Jl. Siwalankerto 121-131, Surabaya 60236, INDONESIA \\ Corresponding author; Email: *bramasta@petra.ac.id; altre@petra.ac.id
}

\begin{abstract}
The development of technology cannot be separated from the development of science, including the learning method. There is an elective course named Virtual Reality Architecture in the Architecture Department of Petra Christian University. This course focuses on the process of learning architecture at the stage of presenting and communicating ideas. The virtual technology used as a learning method includes three types of technology, animation, augmented reality, and virtual reality. The three technologies are elaborated as a simulation method. The simplicity of its application can be seen in the support for hardware, software, and special devices used by students in their daily lives. This study aims to test the achievement of goals at the final level of learning. Students who have attended this lecture are then interviewed and observed to prove whether this simple virtual technology can support the learning process in the architecture study program.
\end{abstract}

Keywords: Virtual reality; augmented reality; architectural presentation.

\section{INTRODUCTION}

Architectural design is the process of generating ideas for spatial design and building forms in a particular context (Plowright, 2014). Communicating the results of ideas can be done with presentation techniques (Canizares, 2020). The presentation of architectural designs has evolved from time to time, from manual hand drawings to digital technology (Webster, 1997). The visual representation process, which is closer to reality and more immersive, will make the communication process of architectural ideas more helpful (Chang \& Szalapaj, 2000). The development of digital virtual visualization technology extends to all fields, including architecture. Design based on visual ideas is considered very suitable and can be helped by using virtual reality technology (Stonorov, 2018). With the support of increasingly affordable tools, the implementation can reach many layers of users. Architecture students \& education is one layer. In the process of architectural education, students cannot be separated from exploring ideas for the needs of fulfilling the competency of space design skills and building shapes (Aslesen et al., 2019).

In supporting the design process, students can choose an elective course in the Petra Christian University architecture study program, namely Virtual Reality Architecture AR4260. It tries to introduce and understand the stage of simple technical implementation with the design object they are working on in the design studio. Students are asked to produce a digital visualization with the help of technology, using software (SketchUp modeling, Twinmotion visuali- zation, and google virtual tour visual viewer) and hardware (laptops, head use visualization devices, smartphones) introduced during the lecture. Of course, this technology needs to be supported by good software and hardware (Hong et al., 2019). However, this course tries to see a more straightforward opportunity from applying this virtual visualization technique. There are at least three design communication virtualizations as visualization methods; the first is animation-based, augmented reality, and virtual reality. The most straightforward approach of virtual reality itself is a static panoramic image (Syafril, 2019). The method used is a panoramic image visualization method in the form of a virtual round area. A further technique is to display the panoramic image in real-time. So virtual reality can be used as a presenter of the final product only; it can also be a tool in the design process (Battista, 2021). Of course, the tools help the design process directly, requiring more complicated hardware and software support (Mintorogo, 2000). This process is temporarily not accommodated by the Virtual Reality course. This study aims to see how much impact the implementation of this technology has in its simplest form on the architectural learning process that students carry out. The significant potential is to see and ensure that the relationship of technology in the learning process can have a positive impact (Mitchell, 1995).

\section{LITERATURE REVIEW}

Several studies and publications related to this topic have been carried out, but not many have correlated them in the teaching and learning process 
or education. The gap that appears is that the implementation of this technology is mainly supported by adequate hardware and software. On the occasion of related subject subjects, the technology used is straightforward. One of the latest studies shows that the implementation of virtual reality in learning has a positive impact (Iranmanesh \& Onur, 2021). However, it must be supported by the commonality of its supporters, such as hardware and software (Sapto Pamungkas et al., 2018). Our initial hypothesis is that there will be students who will find this simple technique very helpful. Still, there will be the possibility of a statement that their implementation has not been maximized or that they have not been fully integrated into the process of designing their daily architecture. The opportunity is that some ideal supporting tools are not yet reachable, and the limitations of simplicity are as previously stated (Ceylan, 2020).

\section{Architecture Virtual Technologies}

Virtual Reality is the standard Indonesian term for the term Digital/Virtual Visualization Technologies. Putro said that VR is an application of digital media technology that has many advantages in visualizing three-dimensional objects (H. Putro, 2015). Users can have other visions through this technology and come to the interaction stage in the digital medium. According to him, three-dimensional physical modeling is a method that can help communicate architectural ideas, especially for ideas that they cannot physically implement (Harris, 1998; H. T. Putro et al., 2015)

Virtual reality as a fundamental concept has at least four primary keys in its definition (Lavalle, 2017). Experience from the designed space, point of view, artificial sensory stimulation, and awareness of the virtual world created (Chaturvedi et al., 2011; Wake \& Levine, 2002). The limitation of architectural visualization through the manual method cannot reach most of these keys. In its implementation, too, students will design a space that is expected to emerge experience in experiencing the virtual simulation (Figure 1). We can fulfill virtual reality through 4 essential elements: Virtual Environment, Virtual Presence, Sense Response, and Interactivity (Mihelj et al., 2014). These four essential elements are primarily achieved through the three-dimensional modeling support of a spatial plan. So that the hope, through visualization of virtual reality, designers can more quickly realize and communicate their imagination in spatial visual language (Graafland, 2012). Lavalle emphasizes the success of this technology is its demand for high specification hardware and software, which makes this technology seem exclusive and out of reach for everyone (Lavalle, 2017). It is essential to review the impact of implementing virtual reality with software and hardware that is simpler, more affordable, and easy to obtain in the architectural education process (Goldman \& Zarzycki, 2010).

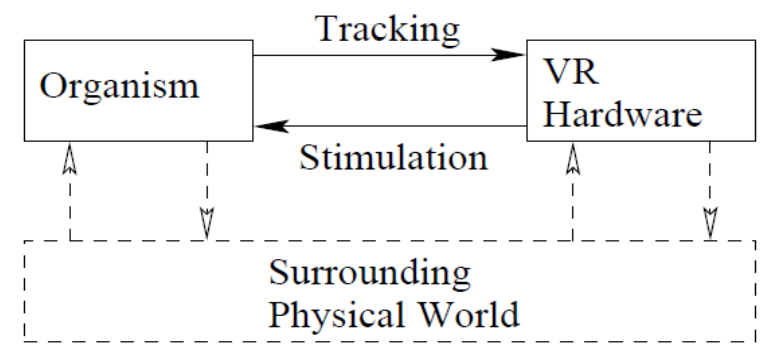

Fig. 1. Schematic of how digital space virtualization works (Surce: Lavalle, 2017)

In the research, literature studies will be carried out to ensure the novelty of the implementation of virtual reality technology in various fields of the architectural design process. The multiple methods referred to include the process of visualization, design simulation, presentation in designing professional architects, researchers, and lecturers-students in the teaching and learning process (Bashabsheh et al., 2019). This study is intended to review the inclusiveness of the use of virtual reality technology in the process of professional design and architectural education, especially the implementation of virtual reality using simple tools that are more accessible to many people. Affordability is a significant factor in the process of architectural education because easy access and affordable tools allow all architecture students to take advantage of this technology anywhere without relying on the existence of expensive physical laboratories (Abdelhameed, 2013). Nowadays, we can make simple applications based on 360-degree visualization, even on lecture assignments. Its simple nature, and the support of unnecessary tools, make simple implementation easy (Syafril, 2019). The question is whether, with this affordable hardware and software, the four critical points of the success of Virtual Reality, which correspond to Lavalle's opinion above, can be achieved. According to LaValle, we can evaluate the quality of the experience felt using virtual reality technology (Lavalle, 2017). Some quality parameters include visual perception (depth, motion, color/ texture), visual rendering, movement, tracking, interaction, audio. From this aspect, a set of experiences will be obtained, which can be evaluated, including the following elements: perception, development recommendations, the convenience of use and development, and further experiments (D'Errico, 2021). 


\section{Virtual Architecture Software \& Hardware}

The two main components of virtualization are hardware and software. In visualization, hardware functions as a making tool (laptop) and a display device (smartphone or head device). Meanwhile, virtual visualization software can take advantage of several variants of the software (Canizares, 2020). In principle, the software can process three-dimensional views and supports the rendering process. There are at least four main hardware displays for the virtualization design (Figure 2) (Syafril, 2019).

\section{- Computing hardware}

This device functions to process data so that it can be compiled and presented in three-dimensional form. If it's just a still image, it can take advantage of simple computing devices. However, if you need a live view, you need more sophisticated computing devices in the context of a design tool.

\section{- Display hardware}

After the image is virtually processed, it needs to be displayed interactively. The least interactive here is that the display device can follow the direction of the user's head movement to display the appropriate direction on the virtual display. The choice is a head device with a viewer using a smartphone or an already integrated head device with the image viewer layer.

\section{- Sound hardware}

There are at least two simulated senses, namely the sense of sight and the sense of hearing. In an architectural context, it is enough that the sense of sight is stimulated. The sound hardware is used to simulate the sounds that may appear in the virtual world to add a natural effect to the user.

\section{- Controller hardware}

Controller hardware can take many forms. The simplest are devices with a gyro sensor, which can detect motion. If movement is more active, then additional hardware such as remote control is needed. In the context of design visualization, this is optional
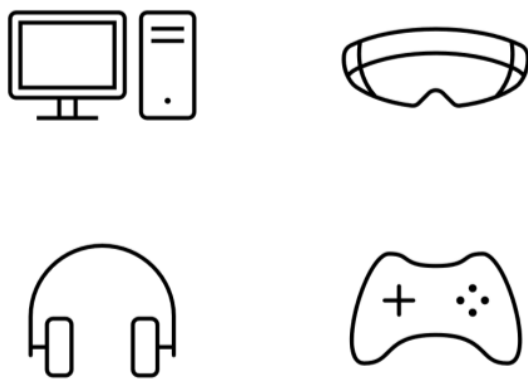

Fig. 2. Virtualization support tools
Hardware, of course, needs software support to work as expected (Figure 3). There are at least three categories of software to support the virtual visual communication process of a design, namely design software, display software, and viewer software (Lavalle, 2017).

\section{- Design software}

Design software, which is software capable of processing designs in a three-dimensional format. The variety is quite large and is not bound by the capability to present the virtualization of reality. Some examples of software in this category include SketchUp, Rhinoceros, AutoCAD.

\section{- Visualization software}

The three-dimensional design needs to be displayed more authentically, both in terms of lighting, materials, and simulations of the surrounding environment. This device will support simple reality virtualization if it supports output processing in panoramic format. Panorama can be in the form of still images or moving images or videos. Some examples of software in this category are Twinmotion, Lumion, Enscape, Sketchup.

\section{- Viewer software}

Several platforms support the display of objects, both animated (video), augmented reality, and vir tual reality (virtual reality). After a virtual image is formed, it needs to be displayed to consume it. We can use the platform in any video platform for video because the virtual animation format is video. Some examples include YouTube, Vimeo, Video Player. Meanwhile, for augmented reality support applications, software capable of displaying three-dimensional projection with the help of a camera is needed. This application runs mostly via smartphone devices, for example, UniteAR, Sketchfab, Sketchup Mobile. Meanwhile, virtual reality viewers take the form of panoramas, in the form of digital platforms, including Google Virtual Tour, Kuula, RoundMe, AirPano, Sketchfab, and so on.

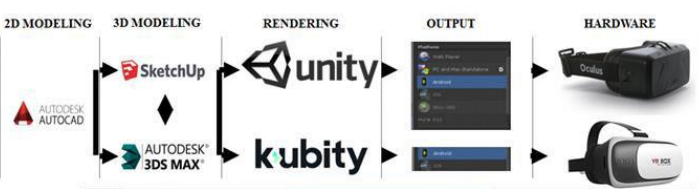

Fig. 3. Software \& Hardware Integration (H. T. Putro et al., 2015)

\section{METHODOLOGY}

This research model is generally qualitative lecture evaluation research. Research is designed to provide experience and capture of meaning created in 
the research field through interactions between researchers and the object of study, namely students participating in the course. Research is qualitative because research variables cannot be quantified or expressed in numbers, such as understanding, perceptions, opinions, etc.

The steps of this research are as follows:

- Preparatory phase: consider selecting courses as the scope of research and establishing research arguments. The chosen course is Virtual Reality Architecture (AR4260) which is an elective course. The evaluation research argument is because the topics and learning objects develop dynamically. Hence, it is necessary to map the impact of lecture activities which is one of the bases for its development.

- Exploration phase: determine the variables that we will seek out through this research, which will help researchers map the impact of the implementation of design virtualization technology in the teaching and learning process. Variables are then determined in line with the lecture process, from beginning, procedure, end, and after the lecture, both in study and work. From this process, then based on the lecture results, the researcher determines the subject of the respondent's matter is interviewed. Subjects are assigned to represent each batch of students and students who get good enough results in these activities.

- Implementation phase: the study was conducted using the online interview method due to limitations due to pandemic conditions. Interviews were conducted separately between sources. Discussions are focused on interview questions related to research variables.

- Concentration phase: research is processed by narrowing the data, analyzing it, and perceiving findings based on previous data processing.

In general, the scheme of this study will find out four main things (research variables), namely (Figure 4)

1. UNDERSTANDING: The level of knowledge of the course participants on the role of applying simple virtual reality technology to the architectural higher education process.

2. MASTERING: The level of mastery of the course participants towards implementing simple virtual technology to the architectural higher education process.

3. IMPACT: Knowing the effects of mastery of simple virtual technology implementation in the architectural higher education process.
4. EXPECTANCE: Knowing the vision of implementing simple virtual technology opportunities in the development of the architectural world in the future.

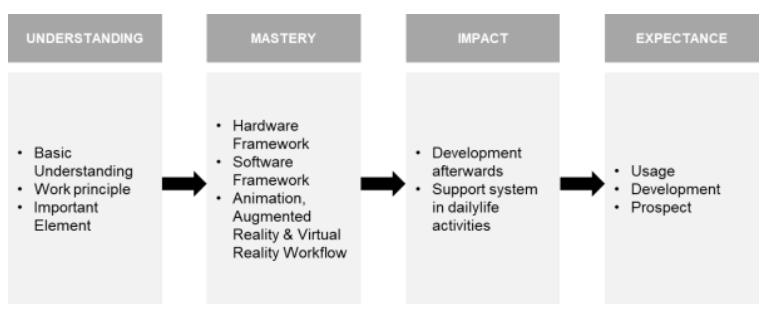

Fig. 4. Research Variable Diagram

Research interview schemes that will support the solution to the above problem formulations are arranged according to the course of the learning process:

1. Motivation \& background for selecting courses

2. Understanding the concept of design virtualization

3. Experience in implementing design virtualization

4. Use and development of advanced virtualization technology

The Virtual Reality Architecture course has been conducted in two periods. The first period is the regular semester, with 19 students with a mixed 2015 and 2016 class composition. While the second period is a short semester with five students in total with the total composition of the 2017 class. This course is designated as part of the elective courses, with competencies. the end to be achieved is as follows:

- Students understand the meaning and development of digital virtual reality technology in presenting architectural designs (understand)

- Students understand how various virtual realitybased applications work in the process of presenting architectural designs (understand)

- Students can implement the concept of digital virtual reality technology in presenting architectural designs (apply)

The learning scheme is divided into two sessions: the beginning to the middle of the semester and the middle to the end of the semester. The first half of the semester is in the form of material lectures and discussions. The final half of the semester contains workshops and a simulation assignment for three virtual technologies: animation, augmented reality, and virtual reality. Hardware support in the form of laptops and smartphones and the software used are:

\section{- Computing software}

To support the process of refining the design before it is presented in three dimensions, several 
applications are used on laptops, namely Sketch Up and Rhinoceros. While the visualization application is simulated with Twinmotion and Lumion.

\section{- Viewing software}

The viewing devices are divided into three categories. For the animation category, the platforms used are You Tube and Streamable. Meanwhile, the platform augmentation category used is Unite $\mathrm{AR}$ and SketchFab. And finally, for the virtual reality category, the visual panoramic platforms used are Kuula, RoundMe, Google Virtual Tour for still images, and Youtube VR for videos.

Below are examples of animated works, augmented reality, and simulated virtual reality.
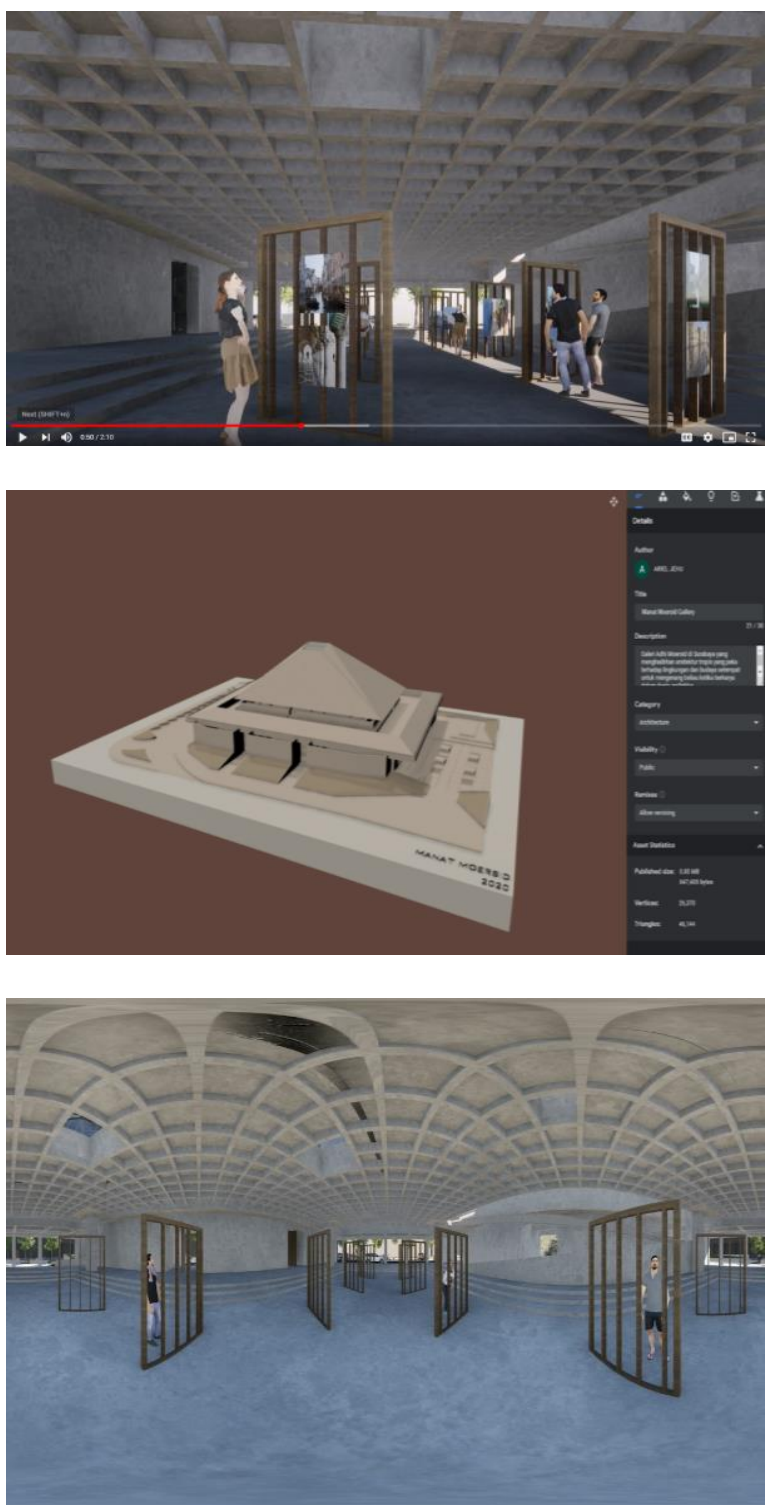

Fig. 5. Student Works of Virtual Reality Tasks (Animation, Augmented Reality \& Virtual Reality); (Source: Ariel Jehu $-\mathrm{B} 12170032)$
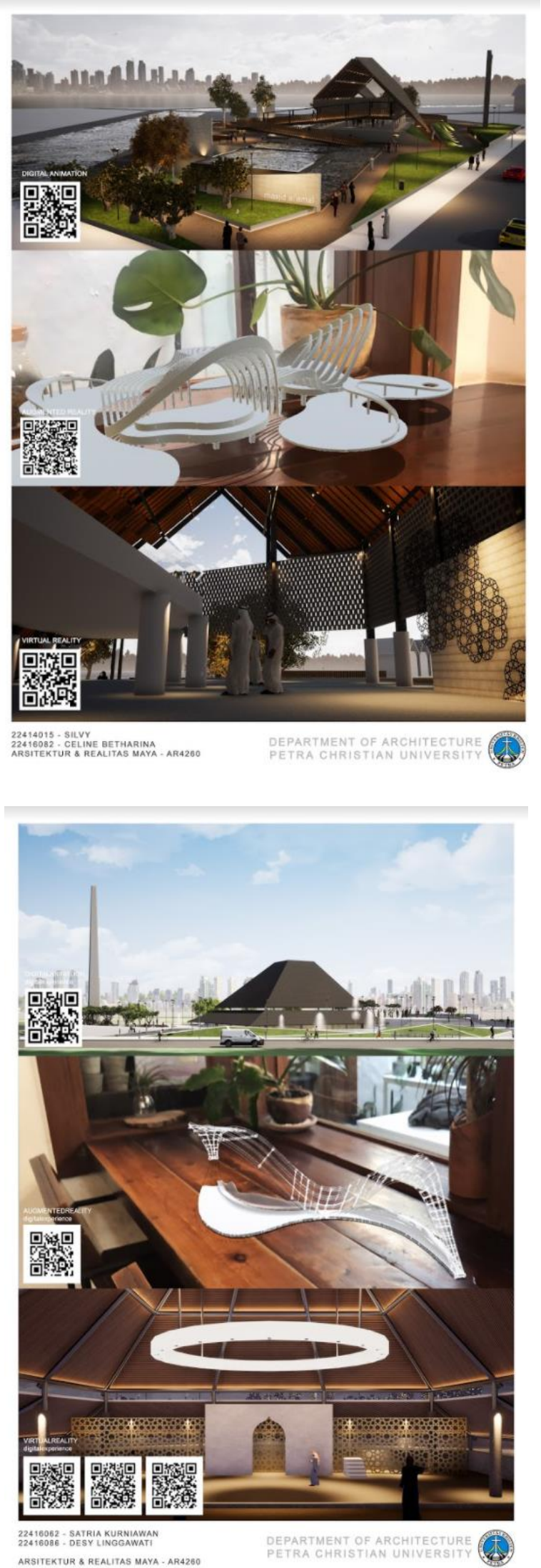

Fig. 6. Student Works Showcase in poster format (Source: Sily 22414015 - Celine 22416082 \& Satria 22416062 Desy 22416086) 


\section{RESULT \& DISCUSSION}

From a total of 24 participants during the two lecture periods, ten respondents were screened using the following criteria;

- Each of them represents the class of 2015, 2016 and 2017

- Enthusiastic enough in the discussion during the lecture

- Have a pretty good value from the lecture

Interviews were conducted using the online Google Meet Meeting platform in December 2020 January 2021. The results of the interviews were recorded in the google form and google online table. The interview design is structured to map the variables of understanding, mastery, impact, and expectation. The interview questions are divided into fivequestion sections.

1. Motivation and background to attend lectures

2. Conception and understanding of animation, augmented reality, and virtual reality

3. Quality of virtual simulations performed

4. Technical implementation and usage experience

5. Use and continued development

From the data process from the interview results above, the following can be interpreted.

\section{Section 01 Background \& Motivation}

Of the ten interview respondents, they answered that none of their motivation to take the course was compulsive. Students choose to take classes with their awareness. The variety ranges from students with zero understanding of this topic to those who understand enough to develop their abilities. From this fact, the data from 10 interview respondents, in our opinion, can be used as valid data.

\section{Section 02 \& 03 Concept of Understanding \& Visualization Quality (UNDERSTANDING VARIABLE)}

They came with their understanding, according to the characteristics of each participant, all of them were able to describe the concept of understanding well. The essence of understanding can be conveyed well from an understanding of digital animation, augmented reality, and virtual reality. Some respondents have graduated from college for a long time, but understanding is not just memorization but complete understanding. For the aspects that influence, although the choices vary, from the descriptions presented, it is clear that they know the working principles and role of implementing this technology, namely increasing the opportunity for understanding in communicating ideas or design.

\section{Section 04 Implementation and Experience (MASTERY VARIABLE)}

From various technologies, applications, and complexity, the selection of animation, augmented reality, and virtual reality only within the scope of presenting ideas can be said to be entirely appropriate. This fact means that by not including the design process, only the design presentation, the tools needed do not need to be too complicated. Each of the respondents can operate, access independently both hardware and supporting software. This argument is because they are making enough use of what they already have themselves.

\section{Section 05 Implementation and Development (IMPACT \& EXPECTATION)}

Most of the respondents were able to see the opportunity to take advantage of this visual virtualization technology in various activities. This statement is, of course, a positive indicator, which shows that this ability does not stop at lectures but extends to jobs, competitions, etc. The use of technology has been able to understand its role, namely that they place this virtual visualization for communication and design presentation. In the end, they also said, from 10 respondents, all of them stated that this technology was up-and-coming. This possibility is supported by the digital era, which increasingly demands technology to be more intense to facilitate the design process.

From the interpretation of the results and interview data, the answers to the research questions are as follows:

- Can the course participants understand the role of implementing simple virtual technology in the architectural higher education process?

They can understand that this virtual visualization technology is intended to facilitate the process of presenting and conveying ideas, especially to laypeople. That is because this technology helps make digital simulations closer to reality, a condition that ordinary people can understand. This condition approaching reality is achieved because the understanding of space becomes more accurate, not cut into pieces. We can simulate visual qualities such as light and materials as naturally as possible. 
- Can the course participants master the implementation of simple virtual technology in the architectural higher education process?

The tools used are most of which are daily design tools. Even for additional tools, they can access it from the cheapest version to the most expensive version. For example, they can replace a VR headset with an inexpensive device like a VR Cardboard with the same essential functions. They can use the average software easily for supporting software because developers present their applications very friendly to users. Complex matters have been simplified in the form of simple icons and buttons. They consciously answer this simple implementation they can master without too hard effort or significant capital. There was no answer to the interview questions that they had difficulty accessing the hardware and operating the software. And the next stage is to present their work virtually.

- Does mastery of implementing simple virtual technologies have an impact on the architectural higher education process?

We can indicate that from its implementation outside of compulsory lecture assignments. Most of them feel significantly helped by this technology. Some consciously add this product as part of a design product even though they are not asked for it. On other occasions, they are pretty observant about using this technology assistance in competition activities and even working in the office. So the impact that appears is positive. They get additional abilities to process and present their design work. And then, they can communicate to clients or design targets interactively and attractively.

- What are the expectations of the opportunities for implementing simple virtual reality technology in the development of the architectural world in the future?

All respondents answered that the opportunities in the future are getting bigger. Their very optimistic answers evidence this. Not only that, but the increasing trend of technology's contribution in life also supports the above statement. But it does not stop at this point. Of course, in line with the development of this virtual visualization technology, we must develop ourselves as well, both in the context of hardware and the ability to utilize an increasingly varied variety of software.

In addition to the above conclusions, we found the following specific points:

\section{Special \& Specific Simulation}

Resource person Gregorius Christian said that one of the advantages of using virtual reality simulation is that it can simulate a particular condition that is difficult to do without virtual or digital media. In the opportunity to work in an architectural studio in Japan, a design needs to simulate the interaction of buildings with rainfall. If the simulation is carried out in real terms, then the model mockup will combine it with a particular water flow so that the studio gets wet or needs a special-designed virtual room. Meanwhile, this is easy to do through digital simulations without the need for a superior physical room.

\section{Understanding of the ordinary people}

Resource person Billy Kianda said that one of the most apparent advantages related to the use of virtual visual technology is that it makes it easier for ordinary people to get an atmosphere simulation precisely as expected by the designer. With the help of digital tools or technology, we can convey ideas easily because experiences are simulated closer to reality. From this, we can understand that architects should understand the client's condition or that the target design is people who cannot understand space. Architects as designers certainly have a good understanding of shadow space, but this is not the case with most non-specialists who are the design targets and potential users of the design space.

\section{Forming a complete atmosphere}

Resource person Billy Kianda revealed that one of the messages to be conveyed through design other than spatial configuration is the ambiance. He can strengthen that by feeling the space as a whole, not just a partial part, with a visualization that approaches the concept of design (aspects of light, materials, etc.). With the help of virtual technology, completeness is easily achieved because the viewer can feel a complete 360-degree space without being divided into certain angles like regular visualizations.

\section{Opportunities for development}

Resource person Billy Kianda also mentioned technology is related to tool support. He uses everyday / daily tech and software. In the implementation questioning session, Billy said that one of the things that spurred the ease of using this virtual technology was because most of the supporting tools were what they already had. Nowadays, tools such as hardware 
and software are easy to get and relatively cheap. Additional tools, too, can be accessed with various versions. For example, headsets, some only have folding cartons, up to expensive devices. The point is that affordability and ease of use can be factors for the sustainability of further developments. For a more advanced stage, the use of more sophisticated tools is certainly possible, but the possibility of daily implementation with a broader range of users becomes more limited.

\section{CONCLUSION}

From the results of the above discussion, it can be concluded that:

- Understanding of the concept and application of virtual visualization technology, be it animation, augmented reality and virtual reality can be mastered by most of the lecturers well

- There is an awareness that this technology has a positive role in presenting ideas or communicating architectural designs to ordinary people. That happens because, through this media, design, and methods in the form of simulations can be presented attractively and variedly, approaching actual conditions that most people easily understand.

- Most agreed that these additional skills support the architectural learning process. That is evidenced by the intensity of the use outside of the mandatory things they have to do, but as other design products that are very helpful in communicating design ideas.

- Future developments tend to be bright, must remain optimistic and adaptive, keep abreast of similar technological developments so that they can continue to be helped and are not burdened because they cannot operate. Good technology is a technology that can make life easier, not what makes us dependent.

From the above conclusions, it is advisable to:

- For study programs and teaching lecturers: to continue developing and integrating science with technological advances so that learning can continue to be relevant to the progress of the times.

- For prospective students: to be aware of their interests and talents, and with full awareness, either independently or in a structured manner, develop abilities in all aspects that support work professionalism.

- For graduates/alumni participating in this course: to continue developing themselves in whatever field they are currently studying. The learning process does not stop when you have graduated, but there is a need for awareness to continue to develop yourself and be relevant to the times.

This study is limited to a reflection of learning in a small-scale class. Hardware applications and support are also limited to simple tools that students use in their daily lives. The potential for future study development is to integrate more advanced technologies and the integration of learning this ability in the design studio as the main course in the architecture study program.

\section{ACKNOWLEDGEMENT}

This study successfully carried out this research with the support of the Faculty of Civil Engineering and Planning, Petra Christian University. Data collection was successfully carried out with the full support of the following alumni: Jimmy Kristanto (22415149), Gregorius Christian Wijaya (22415157), Kevin Ardisa Putra (22416171), Billy Kianda Sanjaya (22416139), Celine Betharina Pudjohadi (22416082), Ariel Jehu (B12170032), Kenny Kurnia Setiono (B12170050), Celicia Aurielle Angdjaja (B1217 0072), Terrance Seymour Luntung (B12170103), Jocelyn Emilia Ulkalvin (B12170136) and all participants in the Virtual Reality Architecture course.

\section{REFERENCES}

Aslesen, H. W., Martin, R., \& Sardo, S. (2019). The virtual is reality! On physical and virtual space in software firms' knowledge formation. Entrepreneurship and Regional Development, 31(910), 669-682. https://doi.org/10.1080/08985626. 2018.1552314

Battista, K. (2021). The White Cube in Virtual Reality. Architectural Design, 91(3), 102-111. https://doi.org/10.1002/ad.2699

Canizares, G. (2020). Technologies of the Virtual Other: Bodies, Users, and Avatars. Journal of Architectural Education, 74(2), 237-249. https://doi.org/10.1080/10464883.2020.1790933

Ceylan, S. (2020). Using virtual reality to improve visual recognition skills of first year architecture students: A comparative study. CSEDU 2020 Proceedings of the 12th International Conference on Computer Supported Education, 2(Csedu), 54-63. https://doi.org/10.5220/00093 46800540063

Chang, D., \& Szalapaj, P. (2000). A study of digital presentation techniques in architecture.

Chaturvedi, A. R., Dolk, D. R., \& Drnevich, P. L. (2011). Design principles for virtual worlds. MIS Quarterly: Management Information Systems, 35(3), 673-684. https://doi.org/10.2307/230428 03. 
D’Errico, M. (2021). Immersive Virtual Reality as an International Collaborative Space for Innovative Simulation Design. Clinical Simulation in Nursing, 54, 30-34. https://doi.org/10.1016/j.ecns. 2021.01 .005

Goldman, G., \& Zarzycki, A. (2010). Digital Media in Architecture and Interior Design - Curriculum Framework REPORT FOR THE SIGGRAPH EDUCATION COMMITTEE Digital Media in Architecture and Interior Design Curriculum Framework.

Graafland, A. (2012). Architecture, Technology and Design. Digital Studio for Research in Design, Visualization and Communication.

Harris, J. (1998). Virtual Architecture: Designing and Directing Curriculum-Based Telecomputing (Issue 1988).

Hong, S. W., El Antably, A., \& Kalay, Y. E. (2019). Architectural design creativity in Multi-User Virtual Environment: A comparative analysis between remote collaboration media. Environment and Planning B: Urban Analytics and City Science, 46(5), 826-844. https://doi.org/10.1177/ 2399808317733267

Iranmanesh, A., \& Onur, Z. (2021). Mandatory Virtual Design Studio for All: Exploring the Transformations of Architectural Education amidst the Global Pandemic. International Journal of Art and Design Education, 40(1), 251-267. https://doi.org/10.1111/jade.12350

Lavalle, S. M. (2017). The Book of Virtual Reality. In Cambridge University Press.

Mihelj, M., Novak, D., \& Beguš, S. (2014). Virtual Reality Technology and Applications. Intelligent Systems, Control and Automation: Science and Engineering.

Mintorogo, D. S. (2000). ARSITEKTUR DVD (Digital Virtual Design). Jurnal Arsitektur DIMENSI, 28(1), 24-30. https://doi.org/10.9744/ dimensi.28.1.
Mitchell, W. J. (1995). The Future of the Virtual Design Studio. In Virtual Design Studio (pp. 5159). Hong Kong University Press. http://www. jstor.org/stable/j.ctt2jc401.13

Plowright, P. (2014). Revealing architectural design : methods, frameworks and tools. Routledge.

Putro, H. (2015). Immersive Virtual Reality for Tourism and Immersive Virtual Reality for Tourism and Creative Industry Development. International Conference on Creative Industry, August, 1-6. https://doi.org/10.13140/RG.2.1. 2102.0002.

Putro, H. T., Yogyakarta, U. T., Reality, V., An, A., For, A., \& Heritage, D. (2015). Kajian Virtual Reality Makalah Studi Mandiri Kajian Virtual Reality Program Studi Teknik Arsitektur dan Perencanaan Oleh Pembimbing: Ir . Jatmika Adi Suryabrata., MSc., Ph. D. January.

Sapto Pamungkas, L., Meytasari, C., \& Trieddiantoro, H. (2018). Virtual Reality As A Spatial Experience For Architecture Design: A Study of Effectiveness for Architecture Students. SHS Web of Conferences, 41, 05005. https://doi.org/ $10.1051 /$ shsconf/20184105005.

Stonorov, T. (2018). Introduction. In The DesignBuild Studio. https://doi.org/10.4324/978131 5650746-1.

Syafril, R. S. (2019). Penerapan Sederhana Virtual Reality Dalam Presentasi Arsitektur. NALARs, 19(1), 29. https://doi.org/10.24853/nalars.19.1. $29-40$.

Wake, W. K., \& Levine, S. L. (2002). Complementary virtual architecture and the design studio. Journal of Architectural Education, 56(2), 1822. https://doi.org/10.1162/10464880260472530

Webster, B. (1997). The Identity of Place. Medieval Scotland, 9-20. https://doi.org/10.1007/978-1349-25402-6_2. 